\title{
Proje Portföyü Seçiminde Çok Boyutlu Sırt Çantası Modeli ve Bulanık Analitik Hiyerarşi Prosesi
}

\author{
Multidimensional Knapsack Model and Fuzzy Analytic Hierarchy Process for Project \\ Portfolio Selection
}

Murat KOCAMAZ ${ }^{1}$

\begin{abstract}
ÖZET
Kaynakların kısıtı olması nedeniyle proje alternatifleri arasından en uygun proje portföyünün seçimi günümüz rekabet koşullarında önem taşıyan bir problemdir. Yaratılacak faydaya göre proje portföyünün belirlenmesi, bütçe ve personel kısıtları göz önüne alındığında karmaşık bir problem haline gelmektedir. Çalışmada, Bulanık Analitik Hiyerarşi Prosesi ile değerlendirme kriterlerinin önemi hesaplanırken, projelerin yarattıkları faydalar puanlama yöntemiyle belirlenmiştir. Bütçe ve personel kısıtlarına göre en uygun proje portföyünün seçimi için Çok Boyutlu Sırt Çantası modelinden faydalanılmıştır. Uygulama kısmında, farklı bütçe ve personel kısıtlarına sahip dokuz proje ele alınmıştır. Çalışma sonucunda, belirli kriterler kapsamında değerlendirilen projelerden, bütçe ve personel kısıtları altında en uygun proje portföyü oluşturulmuştur. Proje değerlendirme ve seçim uygulaması bir çimento üretim işletmesinde, gerçekleştirilmiştir.
\end{abstract}

Anahtar Kelimeler: Çok boyutlu sırt çantası problemi, bulanık analitik hiyerarşi problemi, proje portföyü seçimi

\section{GíRiş}

Planlama dönemlerinde geliştirilen proje alternatifleri arasından en uygun proje portföyü seçimi stratejik işletme yönetimi açısından kritik öneme sahip bir konudur. Kaynakların doğru kullanımı ve projelerden elde edilecek toplam faydanın maksimize edilmesi işletmelerin stratejik hedeflerini etkin bir şekilde gerçekleştirmesi için temel gereksinimlerden biridir. Bu amaçla geliştirilen, sayısal ve sezgisel yöntemlere dayalı birçok proje seçim modeli literatürde yer almaktadır (Coffin ve Taylor III, 1996; Lee ve Kim, 2001; Coldrick ve diğerleri, 2005; Wang ve Hwang, 2005; Carlsson ve diğerleri, 2006,). Çok kriterli karar verme modelleri puanlama, sıralama, karar ağaçları, oyun teorisi, Delphi tekniği, bulanık mantık, analitik hiyerarşi prosesi, hedef programlama, dinamik programlama, doğrusal 0-1 programlama, karesel programlama ve doğrusal olmayan programlama gibi yöntemlerden faydalanmaktadır (Feng ve diğerleri, 2011). Bu mo-

\begin{abstract}
Selection of the most appropriate project portfolio among project alternatives is an important problem in today's competitive environment due to lack of resources. Determination of project portfolio according to benefits is becoming a complex problem when budget and staff constraints are considered. In this study, importance of the evaluation criteria calculated by Fuzzy Analytic Hierarchy Process and the benefits of the projects are determined by the scoring method. For selecting the most appropriate project portfolio according to the budget and staff constraints, Multidimensional Knapsack model was used. In the application, there are nine projects with different budgets and staffing constraints. As a result, optimal project portfolio have been established under budget and staff constraints within projects that are evaluated under certain criteria. Project evaluation and selection was held in a cement production company.
\end{abstract}

Keywords: Multidimensional knapsack problem, fuzzy analytic hierarchy process, project portfolio selection

deller ağırlıklı olarak, yöneticiler tarafından belirlenen kısıtlar altında faydayı maksimize eden proje önceliklendirmeye dayalı yöntemler olmakla birlikte, birden çok kısıtın bulunduğu durumda en iyi proje portföyünü bulanık karar verme yöntemlerinden faydalanarak çözen modellemeler üzerine yapılan çalışmalar sınırlıdır.

Proje sıralama veya en iyi projeyi seçme probleminden farklı olarak, en iyi proje portföyünün belirlenmesinde, kısıtlar dahilinde gerçekleşecek bir veya birden çok projenin toplam faydasının maksimize edilmesi amaçlanmaktadır (Pohekar ve Ramachandran, 2004). Bu kapsamda kimi zaman en yüksek faydayı sağlayan projeler, kısıtlardan tüketecekleri kaynaklar ele alındığında portföy dışında bırakılabilmektedir.

Proje portföyü seçiminin modellenmesi, kısıtlayıcılar açısından olmasa da, yaratılan faydanın tanımlanması açısından kimi zorluklar içermektedir. Özellikle projelerden yaratılması beklenen faydanın tek bir 
değere indirgenmesi bu tip problemlerin uygulama alanı bulmasını zorlaştıran faktörler arasında yer almaktadır (Lee ve Kim, 2000).

Bu makale kapsamında geliştirilen modellemenin ilk aşamasını, proje seçim kriterlerinin Bulanık Analitik Hiyerarşi Proses (BAHP) kullanılarak ağırıklandırılması oluşturmaktadır. Sonrasında hesaplanan bu kriter ağırlıklarıyla projelerin kriterlerden aldıkları puanlar çarpılarak tüm projelerin yaratacakları faydalar hesaplanmıştır.

Çalışmanın ikinci aşamasını, yaratılan faydayı maksimize ederken (Lin ve Yao, 2001) bütçe ve personel kısıtlarını aşmayan en iyi proje portföyü seçimi oluşturmaktadır. Bu seçimin modellenmesinde Çok Boyutlu Sırt Çantası Problemi (ÇBSÇP) kullanılmıştır.

\section{OPTIMIZASYON MODELI}

\subsection{Bulanık Analitik Hiyerarşi Prosesi}

Analitik Hiyerarşi Prosesten (Saaty, 1980) farklı olarak BAHP kriterlerin birbiri ile göreceli önemlerinin belirlenmesinde üçgensel bulanık sayılardan faydalanır. Bulanık mantık ve bulanık küme çalışmaları ilk olarak Lotfi A. Zadeh (1965) tarafından ortaya atılmıştır. Bulanık mantık teorisine göre kriterlerin belirlenmesinde kesin bir netlik yoktur (Belman ve Zadeh, 1970). İkili mantık gerçek dünyanın belirsizliğini anlatmada yetersiz kalmaktadır. Gerçek hayatta, çözümler genellikle kısmen doğru veya belirli bir olasılıkla doğru ya da yanlış olarak değerlendirilmektedir (Çiçekli ve Karaçizmeli, 2013). Bulanık mantık yönteminde klasik teorideki 1 veya 0 değerleri yerine, 1 ile 0 arasında kalan sonsuz değer seti ile çözüm aranmaktadır (Hsueh ve Yan, 2011). Bu nedenle BAHP üçgensel bulanık sayılardan faydalanır. Şekil.1 ve Denklem.1'de gösterildiği gibi üçgensel bulanık bir sayı üç noktadan oluşur.

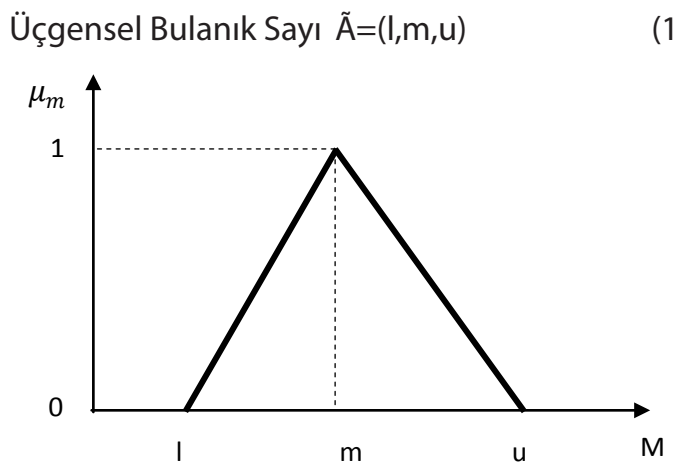

Şekil 1: Üçgensel Bulanık Sayı Ã

Sayının alt (I), ortalama $(\mathrm{m})$ ve üst (u) değerlerini içeren bu üçgensel ifadelerden farklı olarak normal, trapezoid vb. bulanık sayı gösterme biçimleri de mev- cuttur. BAHP'de kullanılan üçgensel bulanık sayılar için gerekecek toplama $\oplus$ (2), çıkarma $\ominus$ (3), çarpma $\otimes(4)$ ve bölme $\oslash(5)$ işlemleri için kullanılan denklemler şu şekildedir;

$$
\begin{aligned}
& \tilde{A}_{1} \oplus \tilde{A}_{2}=\left(I_{1}, m_{1}, u_{1}\right) \oplus\left(I_{2^{\prime}} m_{2^{\prime}} u_{2}\right) \\
& =\left(l_{1}+u_{2}, m_{1}+m_{2^{\prime}} u_{1}+l_{2}\right) \\
& \tilde{A}_{1} \ominus \tilde{A}_{2}=\left(I_{1}, m_{1}, u_{1}\right) \ominus\left(I_{2}, m_{2}, u_{2}\right) \\
& =\left(I_{1}-u_{2}, m_{1}-m_{2}, u_{1}-I_{2}\right) \\
& \tilde{A}_{1} \otimes \tilde{A}_{2}=\left(\mathrm{I}_{1}, \mathrm{~m}_{1}, \mathrm{u}_{1}\right) \otimes\left(\mathrm{I}_{2}, \mathrm{~m}_{2}, \mathrm{u}_{2}\right) \\
& =\left(\mathrm{l}_{1} \mathrm{I}_{2}, \mathrm{~m}_{1} \mathrm{~m}_{2}, \mathrm{u}_{1} \mathrm{u}_{2}\right) \quad \text { tüm } \mathrm{l}_{\mathrm{i}}>0, \mathrm{~m}_{\mathrm{i}}>0, \mathrm{u}_{\mathrm{i}}>0 \\
& \tilde{A}_{1} \oslash \tilde{A}_{2}=\left(l_{1}, m_{1}, u_{1}\right) \oslash\left(l_{2}, m_{2}, u_{2}\right) \\
& =\left(\mathrm{I}_{1} / \mathrm{u}_{2}, \mathrm{~m}_{1} / \mathrm{m}_{2}, \mathrm{u}_{1} / \mathrm{I}_{2}\right) \text { tüm } \mathrm{I}_{\mathrm{i}}>0, \mathrm{~m}_{\mathrm{i}}>0, \mathrm{u}_{\mathrm{i}}>0
\end{aligned}
$$

BAHP kriterler arasında ikili karşılaştırmalardan faydalanmaktadır. İki kriter birbirine göre kıyaslanırken karar vericinin göreceli değerlendirmesi gerekmektedir (Saghaei ve Didehkhani, 2011). Hiyerarşi $n$ adet kriter içeriyor ise $\mathrm{n} x \mathrm{n}$ boyutunda oluşacak ikili karşılaştırma matrisi için toplam yapılması gereken değerlendirme sayısı şu şekilde hesaplanır (6):

Toplam Değerlendirme Sayısı=n(n-1)/2

BAHP'de kriterler arasındaki sübjektif ilişkilerin tanımlanmasında kullanılan bulanık ölçek Tablo.1'de verilmektedir.

Tablo 1: Kriterler Arasındaki İlişkilere Ait Önem Ölçeği

\begin{tabular}{|c|l|c|c|}
\hline $\begin{array}{c}\text { Bulanık } \\
\text { Sayı }\end{array}$ & \multicolumn{1}{|c|}{ Sözel Tanım } & $\begin{array}{c}\text { Üçgensel } \\
\text { Bulanık } \\
\text { Sayı }\end{array}$ & $\begin{array}{c}\text { Üçgensel } \\
\text { Bulanık } \\
\text { Sayı Eşleniği }\end{array}$ \\
\hline 1 & Eşit Derecede Önemli & $(1,1,3)$ & $(1 / 3,1,1)$ \\
\hline 3 & $\begin{array}{l}\text { Biraz Daha Fazla } \\
\text { Önemli }\end{array}$ & $(1,3,5)$ & $(1 / 5,1 / 3,1)$ \\
\hline 5 & $\begin{array}{l}\text { Kuvvetli Derecede } \\
\text { Önemli }\end{array}$ & $(3,5,7)$ & $(1 / 7,1 / 5,1 / 3)$ \\
\hline 7 & $\begin{array}{l}\text { Çok Kuvvetli } \\
\text { Derecede Önemli }\end{array}$ & $(5,7,9)$ & $(1 / 9,1 / 7,1 / 5)$ \\
\hline 9 & Kesin Önemli & $(7,9,9)$ & $(1 / 9,1 / 9,1 / 5)$ \\
\hline
\end{tabular}

BAHP algoritmasında elde edilen sentez değerlerinin karşılaştııılması ve bu karşılaştırma değerlerinden ağırlık değerlerinin elde edilmesi Chang'in (1996) çalışması esas alınarak yapılmıştır.

$$
\begin{aligned}
& \mathrm{x}=\left(\mathrm{x}_{1}, \mathrm{x}_{2}, \ldots, \mathrm{x}_{\mathrm{n}}\right) \quad \text { ölçüt kümesi } \\
& \mathrm{u}=\left(\mathrm{u}_{1}, \mathrm{u}_{2}, \ldots, \mathrm{u}_{\mathrm{n}}\right) \text { hedef kümesi }
\end{aligned}
$$

Sonraki aşamada her bir ölçüt için $m$ adet genişletilmiş analiz değerleri oluşturulur.

$$
\mathrm{M}_{\mathrm{g}_{\mathrm{i}}}^{1}, \mathrm{M}_{\mathrm{g}_{\mathrm{i}}}^{2}, \ldots, \mathrm{M}_{\mathrm{g}_{\mathrm{i}}}^{\mathrm{m}},(\mathrm{i}=1,2, \ldots, \mathrm{n})
$$

Burada tüm $\mathrm{M}_{\mathrm{g}_{\mathrm{i}}}^{\mathrm{j}}$ 'ler üçgensel bulanık sayıdır.

illk olarak bulanık yapay büyüklük değeri, i. nesne- 
ye göre şöyle tanımlanır:

$$
S_{i}=\sum_{j=1}^{m} M_{g_{i}}^{j} \otimes\left[\sum_{i=1}^{n} \sum_{j=1}^{m} M_{g_{i}}^{j}\right]^{(-1)}
$$

$\sum_{j=1}^{m} M_{g_{i}}^{j}$ değerini elde etmek için m değerleri üzerinde bulanık sayılarda toplama işlemini belirli bir matris için şu şekilde gerçekleştirilir.

$$
\begin{aligned}
& \sum_{\mathrm{j}=1}^{\mathrm{m}} \mathrm{M}_{\mathrm{g}_{\mathrm{i}}}^{\mathrm{j}}=\left(\sum_{\mathrm{j}=1}^{\mathrm{m}} \mathrm{1}_{\mathrm{j}}, \sum_{\mathrm{j}=1}^{\mathrm{m}} \mathrm{m}_{\mathrm{j}}, \sum_{\mathrm{j}=1}^{\mathrm{m}} \mathrm{u}_{\mathrm{j}},\right. \\
& {\left[\sum_{\mathrm{i}=1}^{\mathrm{n}} \sum_{\mathrm{j}=1}^{\mathrm{m}} \mathrm{M}_{\mathrm{g}_{\mathrm{i}}}^{\mathrm{j}}\right]^{-1} \text { ifadesi için } M_{(\mathrm{g})}^{j}(j}
\end{aligned}
$$

ifadesi için $M_{\left(g_{i}\right)}^{j}(j=1,2, \ldots, m)$ değerleri üzerinde bulanık toplama işlemi gerçekleştirilir.

$$
\sum_{\mathrm{i}=1}^{\mathrm{n}} \sum_{\mathrm{j}=1}^{\mathrm{m}} \mathrm{M}_{\mathrm{g}_{\mathrm{i}}}^{\mathrm{j}}=\left(\sum_{\mathrm{i}=1}^{\mathrm{n}} \mathrm{1}_{\mathrm{i}}, \sum_{\mathrm{i}=1}^{\mathrm{n}} \mathrm{m}_{\mathrm{i}}, \sum_{\mathrm{i}=1}^{\mathrm{n}} \mathrm{u}_{\mathrm{i}},\right)
$$

Vektörün tersi ise şu şekilde tanımlanır;

$$
\left[\sum_{i=1}^{n} \sum_{j=1}^{m} M_{g_{i}}^{j}\right]^{-1}=\left(\frac{1}{\sum_{i=1}^{n} u_{i}}, \frac{1}{\sum_{i=1}^{n} m_{i}}, \frac{1}{\sum_{i=1}^{n} 1_{i}}\right)
$$

sonrasında $M_{2}=\left(l_{2^{\prime}} m_{2^{\prime}} u_{2}\right) \geq M_{1}=\left(l_{1}, m_{1}, u_{1}\right)$ olabilirlik derecesi şu şekilde tanımlanır.

$$
\begin{aligned}
& \mathrm{V}\left(\mathrm{M}_{2} \geq \mathrm{M}_{1}\right)=\operatorname{hgt}\left(\mathrm{M}_{1} \cap \mathrm{M}_{2}\right)= \\
& \mu_{M_{2}}(d)\left\{\begin{array}{c}
1, \text { eger } m_{2} \geq m_{1} \\
0, \text { eger } l_{1} \geq u_{2} \\
\frac{l_{1}-u_{2}}{\left(m_{2}-u_{2}\right)-\left(m_{1}-l_{1}\right)}, \text { diger }
\end{array}\right.
\end{aligned}
$$

$M_{1}$ ve $M_{2}$ yi karşılaştırmak için $V\left(M_{2} \geq M_{1}\right)$ ve $V\left(M_{1} \geq M_{2}\right)$ değerlerinin her ikisinin de bulunması gerekir.

Dışbükey bir bulanık sayının olasılık derecesinin $\mathrm{k}$ dışbükey sayıdan, $M_{i}(i=1,2, \ldots, k)$ daha büyük olması aşağıdaki şekilde tanımlanır;

$V\left(M \geq M_{1}, M_{2}, \ldots, M_{k}\right)=V\left[\left(M \geq M_{1}\right)\right.$ ve $\left(M \geq M_{2}\right)$ ve $\ldots$ ve $\left.\left(M \geq M_{k}\right)\right]=\min V\left(M \geq M_{i}\right),(i=1,2, \ldots, k)$

$$
d^{\prime}\left(A_{i}\right)=\min V\left(S_{i} \geq S_{k}\right)
$$

Olarak ele alındığında aşağıdaki ağırlık vektörü elde edilir;

$$
W^{\prime}=\left(d^{\prime}\left(A_{i}\right), d^{\prime}\left(A_{2}\right), \ldots, d^{\prime}\left(A_{n}\right)\right)^{\top},(i=1,2, \ldots, n)(17)
$$

Son olarak hesaplanan ağırlık vektörü aşağıdaki şekilde normalize edilir. Elde edilen W değeri bulanık olmayan bir sayıdır ve kriterlerin ağırlıklarını ifade etmektedir.

$$
W=\left(d\left(A_{i}\right), d\left(A_{2}\right), \ldots, d\left(A_{n}\right)\right) \wedge T
$$

\section{2. Çok Boyutlu Sırt Çantası Problemi}

Sırt Çantası Probleminde, bir sırt çantası içine alınabilecek objeler, çantayı taşıyacak kişiye sağladıkları fayda açısından tek tek değerlendirilmekte ve çantanın taşıma kapasitesi göz önüne alınarak bu objelerden oluşan en uygun portföy oluşturulmaktadır. Modelin yapısı gereği, objelerin yarattıkları fayda ve her bir objenin ağırlığı bir arada değerlendirilerek taşınacak çanta içine, ağırlık kriterini aşmadan, toplamda yaratılacak fayda maksimum olacak şekilde objeler seçilmektedir.

Sırt Çantası Probleminin proje seçimine benzetilmesinde ise, her bir proje alternatifinin işletmeye sağlayacağı fayda ve her bir projenin kaynak kullanımının net bir şekilde belirlenmesi gerekmektedir. Literatürde bu konu ile ilgili çok çalışma bulunmamasının sebebi, projelerde yaratılan faydanın tek bir değere indirgenmesinde yaşanan zorluklar ve proje sayısının çok olması durumunda sırt çantası probleminin optimal çözüm arayışındaki güçlükler gösterilmektedir.

Proje havuzundan, farklı proje kısıtları altında maksimum fayda sağlanacak en iyi proje portföyünün seçilmesi proje yönetiminde önem teşkil eden konulardan birisi olarak yer almaktadır. Toplam $\mathrm{n}$ adet proje için $\mathrm{m}$ adet kısıtın yer aldığı bir modelde, projelerin seçilme veya seçilmeme durumu dikkate alınarak toplam fayda maksimize edilmeye çalışıır. $\mathrm{Bu}$ modelin genelleştirilmiş hali şu şekilde tanımlanır;

n: proje sayısı

m:kısıt sayısı

$p_{j}$; j projesinden sağlanacak fayda

$x_{i}:$ j projesinin seçilme durumu

$c_{i}:$ i kısıtının kapasitesi

$\mathrm{w}_{\mathrm{ij}}$;j projesinin i kaynağını kullanım değeri

$$
\begin{aligned}
& \text { maksimizasyon } \mathrm{z}=\sum_{\mathrm{j}=1}^{\mathrm{n}} \mathrm{p}_{\mathrm{j}} \mathrm{x}_{\mathrm{j}} \\
& \text { kısıtlayıcılar } \sum_{\mathrm{j}=1}^{\mathrm{n}} \mathrm{w}_{\mathrm{ij}} \mathrm{x}_{\mathrm{j}} \leq \mathrm{c}_{\mathrm{i}} \\
& \mathrm{j}=1, \ldots, \mathrm{n} \\
& \mathrm{i}=1, \ldots, \mathrm{m} \\
& \mathrm{x}_{\mathrm{i}}=0 \text { veya } 1
\end{aligned}
$$

Proje portföyü seçimi bu şekli ile literatürde yer alan çok boyutlu sırt çantası problemi olarak modellenebilir. $\mathrm{n}$ adet projenin yarattığı fayda ve $\mathrm{m}$ adet kaynağın kapasite sınırı

$$
\begin{aligned}
& \mathrm{p}_{\mathrm{j}}>0 \\
& \mathrm{c}_{\mathrm{i}}>0
\end{aligned}
$$

olarak verilmektedir. Ayrıca her bir j projesi i kaynağından $\mathrm{w}_{\mathrm{ij}}>0$

Kadar kaynak kullanmaktadır. $\mathrm{x}$ değerlerinin 0 veya 1 olma durumu projenin seçilip seçilmediğini ifade etmektedir. Amaç toplam faydayı maksimize edecek şekilde proje portföyünün belirlenmedir. 


\section{METODOLOJI}

\subsection{Problemin Tanımlanması}

Çalışmada örnek olarak ele alınan problemde, 8 adet proje içerisinden yaratılan fayda maksimize edilecek şekilde en uygun proje portföyünün seçimi hedeflenmektedir.

Proje portföyünün seçimi için ilk aşama projeler tarafından yaratılan faydanın hesaplanmasıdır. Bu değerler projelerin seçilip seçilmemesinde büyük önem taşımaktadır. Çalışmada önerilen modele göre, projeler belirli kriterler göz önünde alınarak puanlandırılacak, her bir kriterin BAHP ile hesaplanan ağırlıkları ile çarpılarak yarattıkları fayda hesaplanacaktır.

Projeler, yaratılan değerin ölçülmesi açısından 6 farklı kriter ile üst yönetim tarafından değerlendirilmiştir. Bu değerlendirme kriterleri şirketin gizlilik politikası nedeniyle sırasız bir şekilde; genel ekipman verimliliği, enerji verimliliği, süreçlerde kolaylık sağlama, birimler arası entegrasyon, çevreye etkisi, hizmet ömrü olarak verilmektedir.

İkinci aşamada projelerin her bir kriterden aldıkIarı puanların tanımlanması yer almaktadır. Kriterlerin ağırlıkları ile çarpıldıktan sonra bu puanlar her bir proje için tek bir fayda değerine dönüşecektir.

Üçüncü aşamada ise projelere ilişkin kısıtlar ve proje maliyet bilgileri ÇBSÇP'ne benzetilerek yarattıkları fayda maksimize edilecek şekilde çözümlenecektir. Bu aşamada projelere ilişkin 2 adet kısıt tanımlanmıştır. Bunlardan ilki proje maliyeti, diğeri ise projede yer alması beklenen personel sayısıdır.

BAHP yöntemine uygun olarak örnek 6 adet kriterin ikili karşılaştırma matrisi Tablo.2'de verilmektedir.

Tablo 2: Proje Seçim Kriterlerinin İkili Karşılaştırılma Matrisi

\begin{tabular}{|c|c|c|c|c|c|c|c|c|c|c|c|c|c|c|c|c|c|c|}
\hline & \multicolumn{3}{|c|}{ K1 } & \multicolumn{3}{c|}{ K2 } & \multicolumn{3}{c|}{ K3 } & \multicolumn{3}{c|}{ K4 } & \multicolumn{3}{c|}{ K5 } & \multicolumn{3}{c|}{ K6 } \\
\hline K1 & 1 & 1 & 1 & 1 & 1 & 3 & 3 & 5 & 7 & 1 & 3 & 5 & 1 & 3 & 5 & 3 & 5 & 7 \\
\hline K2 & 0,33 & 1 & 1 & 1 & 1 & 1 & 3 & 5 & 7 & 1 & 3 & 5 & 1 & 1 & 3 & 3 & 5 & 7 \\
\hline K3 & 0,14 & 0,20 & 0,33 & 0,20 & 0,33 & 1 & 1 & 1 & 1 & 1 & 1 & 3 & 0,20 & 0,33 & 1 & 1 & 1 & 3 \\
\hline K4 & 0,20 & 0,33 & 1 & 0,20 & 0,33 & 1 & 0,33 & 1 & 1 & 1 & 1 & 1 & 1 & 1 & 3 & 1 & 3 & 5 \\
\hline K5 & 0,20 & 0,33 & 1 & 0,33 & 1 & 1 & 1 & 3 & 5 & 0,33 & 1 & 1 & 1 & 1 & 1 & 1 & 3 & 5 \\
\hline K6 & 0,14 & 0,20 & 0,33 & 0,14 & 0,20 & 0,33 & 0,33 & 1 & 1 & 0,20 & 0,33 & 1 & 0,20 & 0,33 & 1 & 1 & 1 & 1 \\
\hline
\end{tabular}

Kriterlerin ağırlıkları belirlendikten sonra BAHP yöntemine göre her bir kriter için projelerin ikili karşılaştırmalarının yapılması gerekmektedir. Örnekteki projelerin, proje maliyeti ve projede ihtiyaç duyulan personel sayısı kısıtlarının bulunması en iyi projelerin seçiminin yapılmasına olanak vermemektedir. Bunun yerine amaç fonksiyonu projelerden sağlanacak toplam faydaya odaklanmaktadır. Bu nedenle çözüm aşamasında, projelerin ikili kıyaslanması yerine puanlama yöntemi kullanılmıştır. Projelerin gerçekleştirilmesi sonucunda yaratılacak faydanın tek bir değere indirgenebilmesi için 8 adet projenin 6 adet kriteri ne ölçüde karşıladığı 0-100 puan aralığında üst yönetim tarafından değerlendirilmektedir. Bu değerlendirme tamamlandığında BAHP ile hesaplanan kriter ağırlıkları, kriter puanları ile çarpılarak proje değerleri hesaplanacaktır. Projelerin her bir kriterden aldığı puanlar, projelerin maliyetleri ve gerekli personel sayıları Tablo.3'de verilmektedir. Proje maliyetleri tahmini olup gerekli personel ihtiyaçları proje tekliflerinin geldiği birim yöneticileri tarafından atanmıştır.
Tablo 3: Projelerin Kriterlerden Aldığı Puanlar, Projelerin Maliyetleri ve Gerekli Personel Sayıları

\begin{tabular}{|l|c|c|c|c|c|c|r|c|}
\hline & K1 & K2 & K3 & K4 & K5 & K6 & $\begin{array}{c}\text { Proje } \\
\text { Maliyeti }\end{array}$ & $\begin{array}{c}\text { Gerekli } \\
\text { Personel }\end{array}$ \\
\hline P1 & 50 & 40 & 40 & 35 & 40 & 35 & 150 & 1 \\
\hline P2 & 85 & 75 & 60 & 85 & 90 & 65 & 800 & 3 \\
\hline P3 & 55 & 50 & 65 & 40 & 45 & 55 & 850 & 3 \\
\hline P4 & 60 & 80 & 50 & 75 & 80 & 55 & 450 & 3 \\
\hline P5 & 70 & 35 & 70 & 65 & 60 & 55 & 200 & 2 \\
\hline P6 & 75 & 65 & 65 & 75 & 75 & 70 & 1000 & 5 \\
\hline P7 & 80 & 100 & 80 & 65 & 100 & 90 & 750 & 2 \\
\hline P8 & 55 & 65 & 55 & 65 & 55 & 50 & 450 & 1 \\
\hline
\end{tabular}

\subsection{Problemin Çözümü}

BAHP kullanılarak 6 kritere ait ikili karşılaştırmaların semantik boyut değerleri hesaplanmıştır. Bu aşamada elde edilen değerler Tablo.4'te verilmektedir. 
Tablo 4: Seçim Kriterlerinin Semantik Boyut Değerleri

\begin{tabular}{|c|c|c|c|c|c|c|}
\hline & K1 & K2 & K3 & K4 & K5 & K6 \\
\hline K1 & 1 & 1 & 1 & 1 & 1 & 1 \\
\hline K2 & 0,9477 & 1 & 1 & 1 & 1 & 1 \\
\hline K3 & 0,4222 & 0,4695 & 1 & 0,8352 & 0,7208 & 1 \\
\hline K4 & 0,5703 & 0,6235 & 1 & 1 & 0,8759 & 1 \\
\hline K5 & 0,6819 & 0,7401 & 1 & 1 & 1 & 1 \\
\hline K6 & 0,1223 & 0,1615 & 0,8834 & 0,6229 & 0,4834 & 1 \\
\hline
\end{tabular}

Tablo 4'teki ikili karşılaştırmaların sentetik boyut değerlerinin her satırdaki en küçük değer alınarak normalizasyon yapılmaktadır. Buna göre;

$$
W^{\prime}=(1 ; 0,9477 ; 0,4222 ; 0,5703 ; 0,6819 ; 0,1223)
$$

$\mathrm{Bu}$ değerler normalize edilerek her bir kriterin ağırlığı hesaplanmış olmaktadır. Buna göre;

$$
W=(0,2671 ; 0,2531 ; 0,1128 ; 0,1523 ; 0,1821 ; 0,0327)
$$

Kriterlerin ağırlıkları tanımlandıktan sonra, her bir kriter ağırlığı ile projelerin bu kriterlerden aldığı puanlar çarpılarak projelerden elde edilmesi beklenen fayda değerlerinin hesaplanmasına geçilir. Buna göre hesaplanan proje değerleri Tablo.5'te verilmektedir.

Tablo 5: Proje Değerleri

\begin{tabular}{|c|c|c|c|c|c|c|c|}
\hline & K1 & K2 & K3 & K4 & K5 & K6 & $\begin{array}{c}\text { Proje } \\
\text { Değeri }\end{array}$ \\
\hline W & 0,2671 & 0,2531 & 0,1128 & 0,1523 & 0,1821 & 0,0327 & \\
\hline P1 & 50 & 40 & 40 & 35 & 40 & 35 & 41,75 \\
\hline P2 & 85 & 75 & 60 & 85 & 90 & 65 & 79,91 \\
\hline P3 & 55 & 50 & 65 & 40 & 45 & 55 & 50,76 \\
\hline P4 & 60 & 80 & 50 & 75 & 80 & 55 & 69,70 \\
\hline P5 & 70 & 35 & 70 & 65 & 60 & 55 & 58,07 \\
\hline P6 & 75 & 65 & 65 & 75 & 75 & 70 & 71,18 \\
\hline P7 & 80 & 100 & 80 & 65 & 100 & 90 & 86,75 \\
\hline P8 & 55 & 65 & 55 & 65 & 55 & 50 & 58,89 \\
\hline
\end{tabular}

Sonraki aşamada, hesaplanan proje değerleri ve her bir proje için gerekli personel sayısı ile proje maliyetlerini içine alan bir ÇBSÇ modeli oluşturulmuştur. Oluşturulan bu modele göre projelerin seçilip seçilmemesi 0-1 ikili değer olarak, personel ve maliyet bilgileri ise kısıt olarak gösterilmektedir.

Projelere ayrılan toplam bütçe 2.000 ve yine atanabilecek toplam personel sayısı 10 kişi üst yönetim tarafından model kısıtları olarak belirlenmiştir. Personelin eş zamanlı olarak birden fazla projede yer almasına izin verilmemektedir.

Tüm bu veriler doğrultusunda ÇBSÇP doğrusal programlama kullanılarak modellenebilmekte ve bulunan çözüm kısıtlar doğrultusunda optimum değeri vermektedir. Modelin amaç fonksiyonu ve kısıtları aşağıda verilmektedir;
Amaç Fonksiyonu:

Maks $Z=p_{1} x_{1}+p_{2} x_{2}+p_{3} x_{3}+p_{4} x_{4}+p_{5} x_{5}+p_{6} x_{6}+p_{7} x_{7}+p_{8} x_{8}(21)$

Personel Kısıtı:

$\mathrm{w}_{\mathrm{p} 1} \mathrm{x}_{1}+\mathrm{w}_{\mathrm{p} 2} \mathrm{x}_{2}+\mathrm{w}_{\mathrm{p} 3} \mathrm{x}_{3}+\mathrm{w}_{\mathrm{p} 4} \mathrm{x}_{4}+\mathrm{w}_{\mathrm{p} 5} \mathrm{x}_{5}+\mathrm{w}_{\mathrm{p} 6} \mathrm{x}_{6}+\mathrm{w}_{\mathrm{p} 7} \mathrm{x}_{7}+\mathrm{w}_{\mathrm{p} 8} \mathrm{x}_{8} \leq \mathrm{w}_{\mathrm{p}}(22)$

Bütçe Kısıtı:

$w_{b 1} x_{1}+w_{b 2} x_{2}+w_{b 3} x_{3}+w_{b 4} x_{4}+w_{b 5} x_{5}+w_{b 6} x_{6}+w_{b 7} x_{7}+w_{b 8}$ $\mathrm{x}_{8} \leq \mathrm{w}_{\mathrm{b}}$

Proje Seçilme Durumu;

$x_{1}, x_{2}, x_{3}, x_{4}, x_{5}, x_{6}, x_{7}, x_{8}=(0,1)$

Bu modelleme altında problemin çözüme girecek olan denklemleri şu şekilde tanımlanabilir;

Maks $Z=41,75 x_{1}+79,91 x_{2}+50,76 x_{3}+69,70 x_{4}+58,07 x_{5}+$ $71,18 \mathrm{x}_{6}+86,75 \cdot \mathrm{x}_{7}+58,89 \mathrm{x}_{8}$

$1 x_{1}+3 x_{2}+3 x_{3}+3 x_{4}+2 x_{5}+5 x_{6}+2 x_{7}+1 x_{8} \leq 10$

$150 \mathrm{x}_{1}+800 \mathrm{x}_{2}+850 \mathrm{x}_{3}+450 \mathrm{x}_{4}+200 \mathrm{x}_{5}+1000 \mathrm{x}_{6}+750 \mathrm{x}_{7}+$ $450 \mathrm{x}_{8} \leq 2000$

$\mathrm{x}_{1}, \mathrm{x}_{2}, \mathrm{x}_{3}, \mathrm{x}_{4}, \mathrm{x}_{5}, \mathrm{x}_{6}, \mathrm{x}_{7}, \mathrm{x}_{8}=(0,1)$

Yapılan doğrusal programlama çözümü sonrasında elde edilen sonuçlar Tablo.6'da verilmektedir.

Elde edilen çözüme göre toplam 5 adet proje seçilmiş, projelere ayrılan bütçenin tamamı kullanılmıştır. Çözüm maksimum faydayı elde ederken projelere ayrılan 10 personelden sadece 9'u kullanılmıştır.

Tablo 6: Doğrusal Programlama Modeli ile Elde Edilen Değerler

\begin{tabular}{|l|c|c|c|}
\hline & $\begin{array}{c}\text { Projenin } \\
\text { Seçilme } \\
\text { Durumu }\end{array}$ & $\begin{array}{c}\text { Kullanılan } \\
\text { Personel } \\
\text { Sayısı }\end{array}$ & $\begin{array}{c}\text { Bütçe } \\
\text { Harcaması }\end{array}$ \\
\hline 1. Proje & 1 & 1 & 150 \\
\hline 2. Proje & 0 & - & - \\
\hline 3. Proje & 0 & - & - \\
\hline 4. Proje & 1 & 3 & 450 \\
\hline 5. Proje & 1 & 2 & 200 \\
\hline 6. Proje & 0 & - & - \\
\hline 7.Proje & 1 & 2 & 750 \\
\hline 8. Proje & 1 & 1 & 450 \\
\hline Toplam & 5 & 9 & 2000 \\
\hline
\end{tabular}




\section{SONUÇ}

Proje seçimi etkin bir stratejik yönetimin temel unsurlarından birisidir. Proje portföyü belirlenirken, bütçe ve personel kısıtları göz önüne alınarak, alternatif projeler arasından toplam faydayı maksimize edecek projelerin seçilmesi önem kazanmaktadır. Seçim problemi, yaratılan değer, proje bütçesi ve personel ihtiyacı değerlerindeki farklılaşmanın artmasıyla zorlaşmakta, yöneticilerin sezgisel kararlar vermesini güçleştirmektedir. Bu nedenle karar vermede faydalanılan sayısal yöntemler, karar vericinin problemi anlama, yorumlama ve değerlendirme yetkinliğini arttırmaktadır.

Makalede önerilen seçim modelinde projelerde yaratılan değerler BAHP ve puanlama yöntemleriyle belirlenmektedir. Bu tip bir modelleme, hem bireysel hem de grup kararlarında kullanım açısından büyük kolaylık sağlamaktadır. Modelin seçim aşamasını oluşturan ÇBSÇP ise çözüm yöntemi olarak 0-1 doğrusal programlama modelinden faydalanmaktadır.
Model bu yönü ile belirlenen proje portföyünden sağlanan faydayı kısıtlar çerçevesinde maksimize etmeyi garantilemektedir.

Bu kapsamda makalede önerilen seçim modeli, klasik sıralama ve puanlama yöntemlerine göre, işletmelerin proje portföyü belirleme kararlarında üstünlük sağlamaktadır. Klasik değerlendirme modellerinde projeler en çok değer yaratandan en az değer yaratana göre sırlanmaktadır. Bu sıralama bütçe ve kapasite kısıtlarının olduğu modellerde yetersiz kalmaktadır. Amacın toplam yaratılacak faydanın maksimizasyonu olduğu bir proje portföyü seçim probleminde kimi zaman alt sıralarda yer alan projelere öncelik verilebilmektedir. Bu kapsamda portföyde yer alacak proje sayısının esnek tutulması ve amaç olarak genel faydaya bakılması gerekliliği doğmaktadır. Önerilen bu çözüm modeli, karar vericinin proje kriterlerinin etkileşimlerini anlamasında ve verdiği kararların sonucu ne şekilde etkilediğini görmesinde kullanılabilecek, hızlı çözüme ulaştıran etkin bir yöntem olarak görülmektedir.

\section{KAYNAKLAR}

Bellman, R. ve Zadeh, L.A. (1970) "Decision-Making in a Fuzzy Environment" Management Science, 17: 141-164.

Carlsson, C., Fuller, R., Heikkila, M. ve Majlender, P. (2006) "A Fuzzy Approach to R\&D Project Portfolio Selection" International Journal of Approximate Reasoning, 44:93-105.

Chang, D.Y. (1996) "Applications of the Extent Analysis Method of Fuzzy AHP” Europen Journal of Operational Research, 95:649-655.

Coffin, M.A ve Taylor, III B.W. (1996) "Multiple Criteria R\&D Project Selection and Scheduling Using Fuzzy Logic" Computers \& Operations Research, 23(3):207-220.

Çiçekli, U.G. ve Karaçizmeli, A. (2013) “BulanIk Analitik Hiyerarşi Süreci ile Başarılı Öğrenci Seçimi: Ege Üniversitesi Iktisadi ve Idari Bilimler Fakültesi Örneği” Ege Stratejik Arasttırmalar Dergisi, 4(1):77-103.

Coldrick, S., Longhurst P., Ivey, P. ve Hannis, J. (2005) "An R\&D Options Selection Model For Investment Decisions" Technovation, 25: 185-193.

Feng, B., Ma, J. ve Fan, Z.P. (2011) "An Integrated Method for Collaborative R\&D Project Selection: Supporting Innovative Research Teams" Expert Systems with Applications, 38: 5532-5543.

Hsueh, S.L. ve Yan, M.R. (2011) "Enhancing Sustainable Community Developments: A Multi-criteria Evaluation Model for Energy Efficient Project Selection" Energy Procedia, 5:135-144.
Lee, J.W. ve Kim, S.H. (2000) "Using Analytic Network Process and Goal Programming for Interdependent Information System Selection" Computers and Operation Research, 27:367-382.

Lee, J.W. ve Kim, S.H. (2001) "An Integrated Approach for Interdependent Information System Project Selection" International Journal of Project Management, 19: 111-118.

Lin, F.T. ve Yao, J.S. (2001) "Using Fuzzy Numbers in Knapsack Problems" European Journal of Operational Research, 135:158-176.

Pohekar, S.D. ve Ramachandran, M. (2004) "Application of Multi-Criteria Decision Making Tosustainable Energy Planning - A Review" Renewable and Sustainable Energy Reviews 8: 365-381.

Saaty, T.L. (1980) The Analytic Hierarchy Process, New York, McGraw-Hill.

Saghaei, A. ve Didehkhani, H. (2011) "Developing an Integrated Model for the Evaluation and Selection of Six Sigma Projects Based on Anfis and Fuzzy Goal Programming" Expert Systems with Applications, 38:721-728.

Wang, J. ve Hwang, W.L. (2005) "A Fuzzy Set Approach for R\&D Portfolio Selection Using a Real Options Valuation Model" The International Journal of Management Science, 35:247-257.

Zadeh, L.A. (1965) "Fuzzy Sets" Information and Control, 8:338-353. 